DOI: $10.53075 /$ ljmsirq3356760

DOI Url: http://doi.org/10.53075/ljmsirq3356760

\title{
ASSESSING THE RATE OF ANTIRETRO VIRAL THERAPY ADHERENCE AMONG PEOPLE LIVING WITH HIV/AIDS IN THE ATWIMA NWABIAGYA MUNICIPAL - ASHANTI REGION
}

\author{
Ernest Boateng \\ Faculty of Public Health and Allied Sciences, Catholic University College of Ghana \\ Email: nanashelter2020@gmail.com \\ Emmanuel Kumah (PhD) \\ Department of Health Administration and Education, University of Education Winneba
}

Copyrights

Copyright for this article is retained by the author, with first publication rights granted to the journal. This is an open-access article distributed under the terms and conditions of the Creative Commons Attribution license (http://creativecommons.org/licenses/by/4.0/)

Received: October $18^{\text {th }}, 2021$

Accepted: November $25^{\text {th }}, 2021$

Published Online: November $2^{\text {th }}, 2021$

\begin{abstract}
At the end of 2018, HIV remains a significant worldwide medical problem and has claimed over 32 million lives. Around 37.9 million individuals were living with the condition at the end of 2018. The pervasiveness of HIV among African adults (15-49 years) was 3-multiple times higher in 2018. When properly followed, ART has been shown to slow the progression of HIV and enable HIV-positive people to live longer, more productive lives. A treatment regimen of at least three antiretroviral (ARV) medications is typically used. Adherence to antiretroviral therapy (ART) is insufficient. Therefore, the study aimed to assess the ART adherence among PLHIV in the Atwima Nwabiagya Municipality to suggest efficient and effective strategies to maximize adherence. A cross-sectional study was employed using quantitative methods to assess the associations between ART adherence and socio-demographic and socioeconomic factors. The site for this study was the ART Clinic at Nkawie Government Hospital, with a study population of all AIDS patients at the ART Clinic. The 450 PLHIV sample included females $(\mathrm{n}=323$, or $71.8 \%)$, while the males were 127 (28.2). Of the 450 participants, $215(47.8 \%)$ reported adherence of 95\%. The mean adherence index was $91.3 \%$. Again, the study showed that those who took a single $(137 ; 30.4 \%)$ ART dose was more comfortable than those who took multiple doses $(313 ; 69.6 \%)$. Discomfort with the ART regimen, financial restrictions, forgetting to take medicine, lack of family support, social stigma, and antiretroviral therapy side effects were all major barriers to adherence in this study. Adherence, as stated by the participants, appeared to be low. Nonadherence is linked to both medical and behavioral factors, such as pausing ART or feeling ART discomfort. Atwima Nwabiagya Municipality, adherence to antiretroviral therapy is low. Before starting antiretroviral treatment, all patients can receive intensive adherence counseling.
\end{abstract}

Keywords: HIV, Antiretroviral therapy, Atwima Nwabiagya

\section{INTRODUCTION}

Human Immunodeficiency Virus (HIV) is a disease that can kill or degrade the capacity of the system and move into a more advanced phase of HIV contamination through acquired immunodeficiency syndrome (AIDS) (WHO 2015). HIV has claimed 25 million lives in the last three decades, making it one of the world's biggest viral degraders (WHO, 2015). HIV is a major global medical issue (WHO, 2015). According to the World Census of AIDS Day, 32 million people worldwide have AIDS, 38 million are infected, and 1.8 million have died due to factors associated with HIV (UNAIDS, 2019). Since the advent of highly active antiretroviral therapy (HAART) in 1996, the causes of mortality and morbidity of HIV-positive people have dramatically improved. (Bica et al., 2015). In recent years, the availability of HIV treatment has increased, with new HIV and AIDS-related deaths records falling (UNAIDS, 2019).

In Sub-Saharan Africa, AIDS has become one of the most common causes of adult death. A higher HIV prevalence rate than the global mean of $0.8 \%$ has been observed in many sub-Saharan African countries. According to UNAIDS, the burden of HIV outbreaks varies considerably from region to continent, with sub-Saharan Africa being the country with the most extreme effects and around $71 \%$ of all citizens living with HIV worldwide (UNAIDS, 2018). This nation is one of the most hit by HIV\&AIDS, with just $12 \%$ of the world's population.

In Ghana, HIV is estimated by UNAIDS at $5.1 \%$ for 15 to 49 years (UNAIDS, 2019). While the prevalence of HIV declined in 2016 from $2.4 \%$ to $2.1 \%$ in 2017 , the occurrence of HIV increased in the same timeframe from $1.1 \%$ to 1.5\%. (NACP, 2017; UNAIDS, 2017; Ghana Aids Commission, 2017). In addition to reducing the mortality and 


\section{International Journal of Multidisciplinary Studies and Innovative Research}

Publisher: Catholic University College of Ghana

ISSN: 2737-7180 (Print), ISSN: 2737-7172 (Online)

DOI: $10.53075 /$ ljmsirq3356760

DOI Url: http://doi.org/10.53075/ljmsirq3356760

morbidity associated with HIV, experimental evidence shows that extended access to ART decreases the chance of HIV transmission by $96 \%$ to sexually active partners (Havlir et al., 2018).

Adherence to ARV treatment is the most challenging part (Bangsberg and Machtinger, 2015; Mini et al., 2012). Adherence is described as the willingness of a patient to follow a treatment plan, take medication at specific periods and frequencies, and comply with diet and other drug restrictions (Muyingo et al., 2012). This is the extent to which a patient uses a medication recommended by a doctor (Bangsberg and Machtinger, 2015). Failure to conform to these measures, on the other hand, can give rise to the development of resilient strains (UNAIDS 2018; Lancet Infectious Diseases 2016) and progression of disease (UNAIDS, 2018). Suboptimal treatment could lead to drug-resistant mutations that can lead to medication failure. This could create a dangerous public health situation and reduce affordable HIV treatment (Portelli et al., 2015).

Adherence to antiretrovirals (ART) is crucial if the differentiation-4 cluster (CD4), virus load, and life cycle are improved while medicines resistance is avoided. For appropriate virus suppression and immune system function in these patients, compliance with 95\% or higher is suggested (Elimination of HIV and AID 2012; Wasti, 2019). It is also seen as an important predictor for patients with HIV/AIDS (Muyingo et al., 2012). Several other studies showed a connection between adherence and clinical outcomes overall (Low-Beer et al., 2000). Compliance with antiviral therapy (ART) is often related to the prolonged suppression of HIV, reduced mortality from CD4 cells, lower tolerances, longer length and improved quality of life (Erah et al., 2018). With only 52\% of the patients who sustained a 90\%-95\% adherence rate at six months, a satisfactory virological response was obtained in 3004 people who initiated protease inhibitor, also reports of consistency, good observance, increased CD4 development, recovery, and decreased mortality were published by Muyingo et al. (2012). The predictive and quality of life of HIV/AIDS patients has increased while reducing the likelihood of disease development and mortality due to antiretroviral therapy (ART), On the other side, increased access to ART was accompanied by a rise in insufficient compliance and a chance of drug tolerance. Keeping an acceptable adherence rate over time is a significant challenge for patients and health workers (Wang et al., 2017).

\section{MATERIALS AND METHODS}

\section{Background of the Study Area}

Atwima Nwabiagya Municipal is one of the forty-three (43) administrative districts and municipalities in the Ashanti Region. It is part of the old Atwima District. It attained its municipal status in March 2018 and is split into Atwima Nwabiagya South and North. The Municipal has a population size of 96,352 (extrapolated from the 2010 population census growth rate of 2.7\%). It shares common boundaries with the Atwima Nwabiagya North to the North, Amansie West District to the South, Kumasi Metropolis to the East and Atwima Mponua District to the West. The Municipal capital is Nkawie. The Municipal has five sub-municipals, namely: Abuakwa, Afari, Asakraka, Kobeng and Nkawie.

\section{Study Design and Type}

The study made use of a cross-sectional survey, using quantitative methods. The study was conducted among adult patients attending government-designated ART sites in the Atwima Nwabiagya Municipal. In this way, study participants were selected to assess data quality and associated factors at a particular time point.

\section{Study Population}

The study population includes all PLHIV, 18 years and above, who had been on ART and attended the clinic in Nkawie Government Hospital for at least 12 months.

\section{Sampling Technique and Sample Size \\ Sample Size Determination}

The estimated minimum sample size for the study was calculated to be 331 based on estimated HIV population who are on ART in Atwima Nwabiagya Municipal. With an expected difference of 5\% the sample size was determined using the Yamane formular:

$\mathrm{n}=$ sample size;

$$
\mathbf{n}=\frac{\mathbf{N}}{1+N\left(e^{2}\right)} \quad \text { Where; }
$$

$\mathrm{N}=$ Population size

$\mathrm{e}=$ Level of precision or sampling of error, which is $\pm 5 \%$

A 95\% confidence level and $\mathrm{P}=.5$ are assumed 


\section{International Journal of Multidisciplinary Studies and Innovative Research}

Publisher: Catholic University College of Ghana

ISSN: 2737-7180 (Print), ISSN: 2737-7172 (Online)

DOI: $10.53075 /$ ljmsirq3356760

DOI Url: http://doi.org/10.53075/ljmsirq3356760

$\begin{array}{ll}\mathrm{n}= & \mathrm{N} \\ 1+\mathrm{N}\left(\mathrm{e}^{2}\right) & \mathrm{n}= \\ & \mathrm{n}=331\end{array}$

After accounting for a $36 \%$ nonresponse rate to potentially take care of eligible respondents that did not respond to at least certain portions of the survey questionnaires, the minimum sample was 450 .

\section{Sampling Technique}

Non-probability sampling techniques were used for the Study. Non-probability sampling established a specific criterion devoid of randomness for selecting the sample. In this sampling technique, samples were selected not to give all the population equal chances of being selected. Convenience sampling was used under the non-probability sampling; at the researcher's convenience regarding data availability and accessibility. With the help of a research assistant, 450 eligible patients were confidently sampled.

\section{Data Collection Tool and Technique}

The study employed both primary and secondary data collection methods. Data were drawn from District Health Information Systems from the Atwima Nwabiagya Districts HART clinic. Socio-demographic and clinical information on patients in the inclusion criteria was gathered from electronic clinical records using a data extraction tool. A designed data collection tool that reflects the various variables under the study was used to gather the data. The data extraction tool was used to extract data on socioeconomic factors. The primary data structured and pre-tested questionnaire with open and closed-ended questions was used to extract data on socioeconomic variables such as income, and time to reach ART centre, family and social support, health facility factors, use of alcohol in the past month, and use of illegal drugs in the past six months preceding the interview, reminder method used to take pills.

\section{Data Analysis}

The data gathered from the respondents was filtered, coded, and entered into a datasheet generated in the Statistical Package for Social Science (SPSS) version 22. The data were double-checked for internal accuracy before being coded. The data were drawn from computerized Health Information systems, folders and registers at the ART centers. Descriptive statistics: mean, frequencies, and standard deviations were used to describe demographic and socioeconomic related characteristics of the participants. Differences between adherence and non-adherence subjects was tested using Students t-test and Chi-Square test for continuous and categorical explanatory variables, respectively. The strength of association between explanatory variables and adherence was measured using logistic regression and reported as odds ratio (OR) with $95 \%$ confidence interval

First, the association was measured for each explanatory variable in univariate model. Then each univariate model was adjusted for age and sex. Patient Attendance-based Defaulting (PAD) indicators were used to determine the degree of adherence. The proportion of patients who visit the clinic on time is measured by PAD. Patients who postponed their appointments and did not return to the clinic within 30 days (1 month) were classified as defaulters.

PAD was determined to serves as a surrogate measure for adherence

$$
P A D=\frac{\text { No. of clinic visit attended }}{\text { Total No. of clinic expected }} \times 100
$$

The denominator (Number of clinics expected) was derived from the Schedule Visit of the ART database. The numerator (Number of clinic visit attended) was also determined from the appointment date of PLHIV in the database.

Patients were described as $100 \%$ adherent if they took all prescribed doses in a month, sub-optimally adherent if they missed 5\% of all prescribed doses in a month and non-adherent if they missed more than 5\% of all prescribed doses in a month. Patients were classified this way based on Bangsberg and Machintinger (2005) reports to achieve durable viral suppression and clinical success; patients require a near-perfect adherence rate of $\geq 95 \%$.

\section{Ethical Consideration}

The study protocol and all other relevant documents were submitted to the Ethics Review Committee of the Ghana Health Service and Nkawie Municipal Hospital for review and approval (GHS-ERC: 038/03/21) before commencement 
ISSN: 2737-7180 (Print), ISSN: 2737-7172 (Online)

DOI: $10.53075 /$ ljmsirq3356760

DOI Url: http://doi.org/10.53075/ljmsirq3356760

of the study. Approval was also sought from the ART centre at Nkawie Municipal Hospital before accessing the database.

\section{DATA ANALYSIS AND RESULTS}

\section{Socio demographic and Socioeconomic Factors Associated with ART adherence}

Table 1 shows the indicators considered under the demographic characteristics of the participants: sex (gender), marital status, religious affiliation, occupation and educational status. The majority of the participants were females $(\mathrm{n}=323$, $71.8 \%)$, while the males were 127 (28.2\%). Age distribution was evenly distributed across the groups. The majority of the participants were married, with a few being separated. There were 79 (17.6\%) singles, $224(49.8 \%)$ married, 45 $(10.0 \%)$ divorced, $6(1.3 \%)$ separated, $68(15.1 \%)$ widows/widowers and $28(6.2 \%)$ cohabiting. With an educational level, $46(10.2 \%)$ did not have any formal education, $60(13.3 \%)$ had up to primary education, $173(38.4 \%)$ had up to JHS, 69 (15.4\%) schooled to SHS, middle school lever 80 (17.8) and 22 (4.9\%) schooled to tertiary. This implied that more respondents had their highest education up to the JHS level and just a few with tertiary level. Economically, the findings indicated that 327 (72.7\%) were employed and 123 (27.3\%) were not employed. The findings clearly show that most people living with HIV were engaged in an active form of employment (traders, seamstress etc.) to sustain them economically.

Findings from the study, as shown in Table 1 indicate that there was no statistically significant difference between adherence and sex $(\mathrm{p}=0.61)$, marital status $(\mathrm{p}=0.30)$, religious affiliation $(0.11)$, educational level $(0.33)$, employment status $(\mathrm{p}=0.54)$. However, there was a direct statistically significant difference between income $(\mathrm{p}=0.02)$ and transportation $(\mathrm{p}=0.02)$ respectfully and adherence, transportation was also a cause to adherence $(\mathrm{p}=0.02)$ and cost of travel to ART center $(\mathrm{p}=0.03)$. In effect income, transportation had a direct influence on adherence as well as age.

Table 1: Sociodemographic and Socioeconomic Factors Associated with ART adherence

$\begin{array}{llll}\text { VARIABLE TOTAL }(\mathrm{N}) & Z^{2} & \text { P-VALUE }\end{array}$

\begin{tabular}{l|lll} 
Sex & $119(26.4)$ & & \\
Males & $331(73.6)$ & & \\
Females & & & \\
Marital Status & $85(18.9)$ & & \\
Single & $199(44.2)$ & & \\
Married & $51(11.3)$ & & \\
Divorced & $7(1.6)$ & & \\
Separated & $74(16.4)$ & & \\
Widow & $34(7.6)$ & & \\
Cohabiting & & & \\
Religion & $293(65.1)$ & & \\
Christian & $138(30.7)$ & & \\
Muslim & $19(4.2)$ & & \\
Traditionalist & & & \\
\end{tabular}

Education

None

$46(10.2)$ 
ISSN: 2737-7180 (Print), ISSN: 2737-7172 (Online)

DOI: $10.53075 /$ ljmsirq 3356760

DOI Url: http://doi.org/10.53075/ljmsirq3356760

Primary 60(13.3)

JHS

$173(38.4)$

24.355

0.33

SHS

69(15.4)

Tertiary

22(4.9)

Middle school lever

80(17.8)

\section{Occupation}

Employed

123(27.3)

Unemployed

323(72.7)

15.289

0.04

Age of Respondents

18-25

13(2.9)

26-35

57(12.7)

36-45

148(32.9)

1.909

0.60

46-55

139(30.8)

55 and above

93(20.7)

Monthly income

Less than 200ghC

304(67.6)

200ghC-500ghC

77(17.1)

$600 \mathrm{ghC}-1000 \mathrm{ghC}$

46(10.2)

1100ghC-1500ghC

$15(3.3)$

Above $1500 \mathrm{gh} \mathbb{C}$

8(1.8)

2.769

0.02

Means of transport

By bus

$355(78.9)$

By foot

22(4.9)

Others

$73(16.2)$

2.698

0.02

Cost of travelling to ART centre

Less than $10 \mathrm{ghC} \quad 233(51.8)$

$10 \mathrm{gh} \mathbb{C} \quad-30 \operatorname{gh} \mathbb{C} 97(21.6)$

$31 \mathrm{ghC}-50 \mathrm{gh} \mathbb{C}$

41(9)

More than 50ghC

79(17.6)

10.564

0.03

Time to reach ART centre

Less than 30 minutes $\quad 242(53.8)$

31-59 minutes $\quad 49(10.9)$

1 hour 54(12)

2-2 hours 52(11.6) 
ISSN: 2737-7180 (Print), ISSN: 2737-7172 (Online)

DOI: $10.53075 /$ ljmsirq3356760

DOI Url: http://doi.org/10.53075/ljmsirq3356760

More than 3 hours $\quad$ 53(11.6) $3.86 \quad 0.27$

\subsection{Proportion of AIDS Patients That Adhere to ART}

In terms of ART conformity, $52.8 \%$ (215) of the participants were not adherent, with a mean adherence index of 91.25 $(47.8 \%)$ and $52.7 \%$ (237) sometimes failing to take their ART. Any $(23.1 \% ; 104)$ discontinued their ART regimen at some stage, with the majority of these instances lasting up to 5 days $(24 \%$; 108), with the key reason being "forgetfulness." More than half of the participants $(56.2 \%$; 253) experienced adverse effects from their existing ART regimen, with heartburn/stomach discomfort $(13.3 \% ; 24)$ and skin rash $(11.7 \% ; 21)$ being the most common. Some participants reported opportunistic infections $(62 \% ; 279)$. Again, the study showed that those who took single (137; $30.4 \%)$ ART dose was more comfortable than those who took multiple doses $(313 ; 69.6 \%)$. All respondents knew the benefits of ART $(100 \%, 450)$, yet most did not concentrate on taking their ART.

Table 1.2 Adherence characteristics of people receiving ART

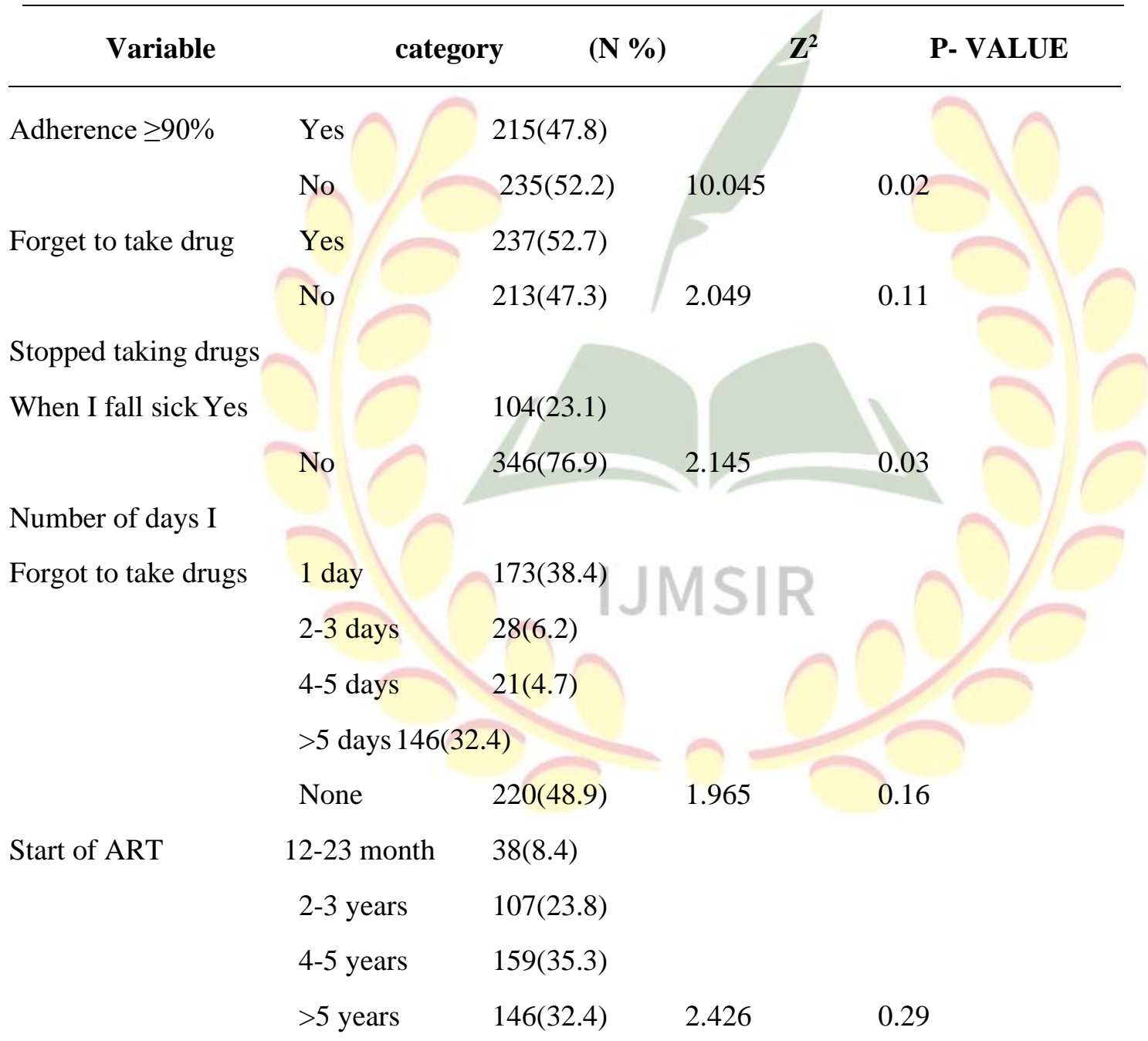

\begin{tabular}{llrrr} 
Importance of ART & Yes & \multicolumn{4}{c}{ 450(100) } \\
& No & $0(0)$ & 32.604 & 0.00
\end{tabular}

Opportunistic infection Yes 279(62)

No $171(38) 2.836 \quad 0.40$ 
DOI: $10.53075 /$ ljmsirq3356760

DOI Url: http://doi.org/10.53075/ljmsirq3356760

\begin{tabular}{lllll}
\hline Side effects of ART & Yes & 258(57.3) & & \\
& No & $192(42.7)$ & 9.582 & 0.43
\end{tabular}

ART drugs taking $\quad$ TDF/3TC/EV 93(20.6)

TDF/3TC/TDG 44(9.7)

TDG 313(69.5)

EV 31(7)

NUP 49(10.8)

$\mathrm{ABC} \quad 23(5)$

$\mathrm{LPR}_{(\mathrm{V})} 55(12.2)$

$\begin{array}{lll}\text { AZT } & 103(23) 10.038 & 0.44\end{array}$

Pills taking in a day Single 137(30.4)

More than one 313(69.6)2.956

\section{DISCUSSION}

\section{Adherence to Antiretroviral Therapy}

Barriers to achieving the UNAIDS 2020 strategic target of achieving $90 \%$ undetected viremia is a great challenge, especially in low-and-middle-income countries such as Sub-Saharan Africa, the success of the set goal. Individual factors such as age, religion, educational status, adherence, and socioeconomic factors such as poverty, not being married, and stigmatization continues to be barriers to undetected viremia, as indicated in the report by WHO (2016). The main reason for clients to be enrolled on antiretroviral therapy is to suppress the replication of RNA of HIV to the barest minimum level to halt the development of drug resistance viruses, restore and improve patients' immunity, combat HIV/AIDS-related events and enhance the life span of the HIV-infected individual as has been researched by Care (2017), Bulage et al. (2017) and Musheke et al. (2013).

According to the results, discontent with the ART regimen was a significant factor in non-adherence. According to a meta-analysis by Clay et al. (2015), PLHIV consuming a single pill is slightly more adherent than someone taking more than one pill at either frequency (odds ratio [OR]: 2.37 [95\% CI 1.68, 3.35], p 0.001), twice-daily MTR (OR: 2.53 [95 $\%$ CI 1.13, 5.66], $\mathrm{p}=0.02$ ), and once-daily multiple tablet regimens (OR: 1. Similarly, Raffi et al. (2015) found that people taking a standard tenofovir-emtricitabine-efavirenz therapy had significantly higher rates of ART adherence ( $86.4 \%>$ one pill once daily; $77.0 \%>1$ daily intake; P 0.0001) than those taking combinations of ART (86.4\% > one pill once daily; $77.0 \%>1$ daily intake; P 0.0001). As a consequence, the policy consequences of the MINSA are essential. (Peruvian Ministry of Health, or Ministerio de Salud del Per) to weigh the cost-benefit calculation of switching ART to a one-pill-per-day routine.

\section{Demographic Characteristic of Participants}

\section{Sex (Gender)}

The study revealed that most of the PLHIV were female as compared to the male population. The finding is in agreement with the global data, which confirms that women contribute to the highest total population of PLHIV (Sheet, Day, \& People, 2018). Most importantly, women in low-middle-income countries contribute significantly to the HIV pandemic, such as those in southern and eastern Africa and some indigenous women in some communities in the world. Many legal and social factors negatively affect women and their ability to make informed choice and decisions that affect their health and total well-being. This exposes vulnerable women to the risk of infection and limits access to adequate, quality and affordable care as indicated by the WHO 2019 Report. Virological failure among women is associated with the 


\section{International Journal of Multidisciplinary Studies and Innovative Research}

Publisher: Catholic University College of Ghana

ISSN: 2737-7180 (Print), ISSN: 2737-7172 (Online)

DOI: $10.53075 /$ ljmsirq3356760

DOI Url: http://doi.org/10.53075/ljmsirq3356760

presence of comorbidities like active tuberculosis, mental conditions, high level of pre-treatment HIV RNA, and late initiation of ART as indicated in the study by Bulage et al. (2017), Hoffman et al. (2016) and Myer et al. (2017).

\section{Age of the participants}

From the study, there is no association between age and adherence (Table 1) but a strong relationship between age and retention to care by PLHIV remains the hope of achieving undetected viremia in the HIV/AIDS continuum of care (Yehia et al., 2016). Various studies support the fact that age significantly impacts viral non-suppression (Bulage et al., 2017; Marcus, Ferrand, Kranzer \& Bekker, 2017). Young adults who are HIV-infected are less likely to be linked and retain in care than adults, leading to high morbidity and mortality rate among this age bracket as a result of viral nonsuppression (NCT03109431, 2017). The study revealed that $33.3 \%$ of the $18-25$ age bracket recorded viral nonsuppression, as indicated in Table 1.2. This agrees with available studies supporting the fact that young adults are at risk of dropping out from care and recording a high level of viremia than adults > 25 years old (De Pundert et al., 2015).

The challenges that are associated with HIV/AIDS, such as anticipated stigma; rejection and sense of shame, fear of disclosure and loss of job, as well as stress, have a more significant impact on the young adults as compared with the adults who have developed the capacity as a result of experience and resources to manage HIV-related stigma and stress (Chhim et al., 2018, Sovershaeva et al., 2019).

There are diverse opinions relating to young adult and adult viral suppression (Yehia et al., 2016). Whereas some published literature attests to the fact that socio demographic data such as age is associated with viral suppression (Connor et al., n.d., Sax et al., n.d.), others have found no such association (Ferreyra et al., 2012, S. Kim, Gerver, Fidler, $\&$ Ward, 2014). HIV-infected young adults experience a worse form of immunological response and viral suppression than adults, leading to high levels of HIV-related morbidity and mortality, especially in low-income countries (Id et al., 2019).

\section{Marital Status}

The study did not find a significant association between marital status $(\mathrm{p}=0.30)$ and adherence, hence viral nonsuppression. Women are more vulnerable to being divorced or going through a separation when their spouses found their HIV positive status (Semvua et al., 2017; Francis et al., 2016, Boireau et al., 2009; de Walque \& Kline 2012). A study in Rwanda and Zambia estimated that over half of all new infections occur within marriage or among couples in cohabitation (International, n.d.).

\section{Religious status}

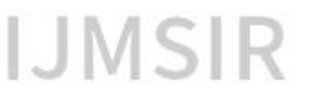

The study did not find a statistically significant relationship between religion $(\mathrm{p}=0.11)$ and adherence, as shown in Table 1. However, the belief in supernatural power is very present among individuals, especially among low -and middleincome countries like Sub-Saharan Africa. The truth accepted by an individual is built on his belief, which impacts any public health interventions (Zou et al., 2009).

The belief in the supernatural presence among people in Sub-Saharan African countries, including Ghana, has a more significant on the effective management of HIV cases, as indicated by Koury (2011). These beliefs in the supernatural give them the support to seek attention from the religious point of view instead of the orthodox medicine. This helps them remain peaceful and strengthened to deal with the new confronted challenges (Denis, 2019).

\section{Socio-economic Impact}

The study assessed the economic status of clients in terms of occupation: employed or unemployed. It was revealed that the employment status $(\mathrm{p}=0.04)$ of participants was statistically significant in influencing adherence, thus supporting the assertion that the individual's economic status has a more significant impact on HIV infection and the success of adherence and attainment of viral suppression (Tomita \& Vandormael, 2019).

Economic constraints impede their ability to afford some hospital cost and payment of treatment in opportunistic infection cases and other costs associated with care. It also affects their nutrition, accommodation, and safety of these HIV-infected individuals (Ezegbe et al., 2019). HIV infection is commonly associated with economically disadvantaged people (Donald et al., 2017). For instance, in the United States of America, people on ART are primarily of lower socioeconomic status with poorer virological and immunological outcomes (Gaps et al., 2018). Most services already 


\section{International Journal of Multidisciplinary Studies and Innovative Research}

Publisher: Catholic University College of Ghana

ISSN: $2737-7180$ (Print), ISSN: 2737-7172 (Online)

DOI: $10.53075 /$ ljmsirq3356760

DOI Url: http://doi.org/10.53075/ljmsirq3356760

offer ARVs for free, removing the need to pay for them as a source of worry and anxiety for program participants. The provision of free antiretroviral treatment, on the other hand, has not removed financial obstacles to adherence.

Transportation also has a relationship with adherence $(\mathrm{p}=0.02)$, ART drugs and services should be decentralized to the CHPS and Health centres within their localities to decrease the burden of transport and also to curb lost to follow-ups and to give of the wrong address, and regular change of phone numbers since the Community Health Nurses are within their zone and will sometimes do home visits. However, the patients complain of stigmatization and fear of mistrust between the health staff within their locality and prefer to travel kilometres for their drugs, although they default. Again, most HIV/AIDS patients have not disclosed their condition to their relatives; hence they hardly get support from their relatives.

Transport costs, especially those in rural areas, maybe substantial compared to incomes and must be competitive with other major expenditures such as food, accommodation, and schooling. In several reports, transport costs were reported as a potential barrier to long-term antiretroviral treatment (Hardon et al. 2007; Mills et al. 2006; Mshana et al. 2006; Mukherjee et al. 2006). However, these trips did not examine the processes by which transport costs could influence compliance and retention with therapy and the solutions used by patients for the increased financial and emotional pressures imposed by transport costs.

\section{Suggestions to Improve ART Service}

The 2013 World Health Organization (WHO) consolidated guidelines for the usage of antiretroviral medications in the treatment and prevention of HIV describe the suite of compliance-enhancing measures and propose that text messages from mobile telephones be used as part of a set of compliance interventions to support ART compliance.

The questionnaire gathered quantitative data from participants. $31.2 \%$ used television and radio programs to alert patients about their medication dates as a reminder. The rest of the respondents, who accounted for $68.8 \%$, used alarm clocks to remember their medications. Most patients were pleased with ART service delivery and had no recommendation for change from this report. The few others felt that the regular supply of medicines should be increased to avoid being rejected due to no medicines. This discovery was also made in Haiti in a report (Koenig et al., 2010). The non-compliance of patients in the therapeutic system, which is due to forgetfulness, was also an issue for ART providers within the trial community. The participants' concern was exclusive to the sample group, and in a Haitian sample, Koenig et al. (2016) identified a related condition.

Encouragement and reminders were measures to improve the ART delivery by the participants. Some, who followed ART well, remembered with their telephone alarm the most critical alert. This research also includes using new approaches to inform people of their drugs, such as using their favorite television and radio programmes. Some had an accurate alarm clock that alerted them of drug time. To improve ART programs through this report, donors, health professionals, the family, and patients would need efficient teamwork. Good anti-retro viral should be delivered consistently and rapidly enough that opioid shortages are prevented

\section{CONCLUSION}

The morbidity and mortality by the virus are reduced by adherence to ART, leading to immunity recovery, reducing the chances of sexually transmitting the HIV to the seronegative partner and offers the hope of ending the HIV epidemic as envisioned UNAIDS goal; 90-90-90, by the year 2020. Viral load count remains the golden tool in determining the success of ART. (Global HIV/AIDS Fact Sheet 2020). The Study revealed that demographic factors such as sex, marital status, religion, level of education, and employment do not influence adherence. However, income (financial constraints) and age are statistically significant and influence adherence. Non-compliance is escalated by TB co-infection, questions regarding the ART regime, and at some point, the interruption of ART. Given the findings of this analysis, the methodological values found, and the variation of the ART management from the proof-dependent criteria for PLHIV globally released, two significant policy consequences exist. Initially, the guidelines for national HIV/AIDS treatment in Ghana should be checked and compared with existing clinical procedures centered on evidence and international norms. Secondly, clinical practices at the local level must be evaluated against national standards to determine the level of compliance of ART regimes; these two suggestions update the professional requirements to ensure that current international guidelines for initiation of ART are available to all Ghanaians and not to those living in the municipality of Atwima Nwabiagya. There must be further Study to create policies to increase the empowerment, self-care, and selfcare of Ghanaian people, leading to better compliance with ART and decreased new infections. To enhance the early 
diagnosis of HIV and prevent complications, procedures should be placed in motion to ensure the cost-efficient allocation of scarce resources.

To conclude, the Study's expertise can be transferred to a permanent local register of the municipality where the regional hospital is situated to assess therapeutic results and shortcomings. To inform the construction of process steps, the register must use the UNAIDS 90-90-90 objectives and then use the five segments of the HIV Care Continuum. This can be achieved by implementing an interdisciplinary, evidence-based programme, such as compliance improving selfmanagement. In general, HIV clinical and pharmacological management efficacy should be measured to recognize best practices and spread helpful "learned lessons" to help make the services in Ghana and the municipality more successful.

\section{ACKNOWLEDGEMENT}

I thank God almighty, colleagues and all those who assisted in contributing to the study or critiquing the manuscript.

\section{REFERENCES}

Ashaba S., Cooper-Vince C., Maling S., Rukundo G.Z., Akena D., Tsai A.C. Internalized HIV stigma, bullying, major depressive disorder, and high-risk suicidality among HIV-positive adolescents in rural Uganda. Glob. Ment. Health. 2018;5: e22. doi: 10.1017/gmh.2018.15.

Averting HIV and AIDS (2018) Universal access to AIDS treatment: Target and challenges [Internet][Cited 2012 March 27]; Available from: http://www.avert.org/universal-access.htm

Bulage, L., Ssewanyana, I., Nankabirwa, V., Nsubuga, F., Kihembo, C., Pande, G., ... Kiyaga, C. (2017). Factors Associated with Virological Non-suppression among HIV-Positive Patients on Antiretroviral Therapy in Uganda, August 2014-July 2015. BMC Infectious Diseases, 17(1), 1-11. https://doi.org/10.1186/s12879-0172428-3

Connor, J. O., Smith, C., Lampe, F. C., Johnson, M. A., Chadwick, D. R., Nelson, M., ... Post, F. A. (n.d.). Durability of viral suppression with first-line antiretroviral therapy in patients with HIV in the UK: an observational cohort study. 295-302.

Chhim, K., Mburu, G., Tuot, S., Sopha, R., Khol, V., Chhoun, P., \& Yi, S. (2018). Factors associated with viral non - suppression among adolescents living with HIV in Cambodia : a cross - sectional study. AIDS Research and Therapy, 1-10. https://doi.org/10.1186/s12981-018-0205-z

Donald, K. A. M., Fernandez, A., Claborn, K., Kuo, C., Koen, N., Zar, H., \& Stein, D. J. (2017). The developmental effects of HIV and alcohol: a comparison of gestational outcomes among babies from South African communities with high prevalence of HIV and alcohol use. AIDS Research and Therapy, 1-10. https://doi.org/10.1186/s12981-017-0153-z

Ezegbe, H., Submitted, P., Fulfillment, P., Health, P., Health, P., Faculty, P., ... Ezegbe, H. (2019). Quality Improvement Initiatives to Strengthen Viral Suppression Among Adolescents Living with HIV in Institute of Human Virology ( IHVN ) Supported Facilities in Abuja Nigeria.

Ghana Aids Commission National and Sub-National HIV and AIDS Estimates and Projections 2017 Report. (2017).

International, P. A. (n.d.). THE Why this film was made: Sex and HIV within Marriage What Can Be Done?

World Health Organization (WHO). (2016). Global AIDS Update 2016. Joint United Nations Programme on HIV/AIDS, (March), 422. https://doi.org/ISBN 978-92-9253-062-5

De Pundert, M. E., Boender, T. S., Hamers, R. L., Sigaloff, K., Kityo, C. M., Akanmu, A. S., Ondoa, P. (2015). Implications of poor CD4 recovery during HIV suppressive ART in Sub-Saharan Africa. Top Antivir Med. 
Denis, P. (2019). HIV / AIDS and religion in sub- Saharan Africa : an emerging field of enquiry. (February 2017). https://doi.org/10.4000/assr.25399

Erah p, Arute J (2018) Adherence of HIV/AIDS patients to antiretroviral therapy in a tertiary health facility in Benin City: African journal of pharmacy and pharmacology Vol.2 (7): 145-152.

Francis, A., Babatunde, S., \& Idemudia, E. (2016). International Journal of Infectious Diseases Marital status and HIV prevalence among women in Nigeria : Ingredients for evidence-based programming. International Journal of Infectious Diseases, 48, 57-63. https://doi.org/10.1016/j.ijid.2016.05.002

Fekete E.M., Wasiams S.L., Skinta M.D. Internalised HIV-stigma, loneliness, depressive symptoms and sleep quality in people living with HIV. Psychol. Health. 2018; 33:398-415. doi: 10.1080/08870446.2017.1357816. [PubMed] [CrossRef] [Google Scholar]

GHANA AIDS COMMISSION National and Sub-National HIV and AIDS Estimates and Projections 2017 Report. (2017).

Hoffmann C, Welz T, Sabranski M, Kolb M, Wolf E, Stellbrink HJ, Wyen C. Higher rates of neuropsychiatric adverse events leading to dolutegravir discontinuation in women and older patients. HIV Med. 2017 Jan;18(1):56-63. [PubMed]

Id, F. K., Esber, A., Musingye, E., Reed, D., Id, A. C., Cham, F., ... Kibuuka, H. (2019). HIV virologic failure and its predictors among HIV-infected adults on antiretroviral therapy in the African Cohort Study. 396, 1-16.

Koenig SP, Bernard D, Dévieux JG, Atwood S, McNairy ML, Severe P, et al. Trends in CD4 Count Testing, Retention in Pre-ART Care, and ART Initiation Rates over the First Decade of Expansion of HIV Services in Haiti. PLOS ONE. 2016;11(2): e0146903. [ Links ]

Marcus, R., Ferrand, R. A., Kranzer, K., \& Bekker, L. G. (2017). The case for viral load testing in adolescents in resource-limited settings. Journal of the International AIDS Society, Vol. 20. https://doi.org/10.1002/jia2.25002

Machtinger E, Bangsberg D (2016) Adherence to HIV Antiretroviral Therapy HIV In Site Knowledge Base Chapter [Internet] [Cited 2012 June 1]; Available from: http://hivinsite.ucsf.edu

Mills EJ, Nachega JB, Bangsberg DR, Sing S, Rachlis B, et al. (2006) Adherence to HAART: A Systematic Review of Developed and Developing Nation Patient- Reported Barrier and Facilitators. PLoS Med 3(11): e438.doi: 10.1371/journal.pmed.0030438.

Mukherjee A, Shah N, Singh R, Vajpayee M, Kabra SK, \& Lodha R (2014). Outcome of highly active antiretroviral therapy in HIV-infected Indian children. BMC Infectious Diseases, 14, 701 https://doi.org/10.1186/s12879014-0701-2 [PMC free article] [PubMed] [Google Scholar

Ministério da Saúde (BR). Guia de tratamento: recomendações para terapia antiretroviral em adultos e adolescentes infectados pelo HIV. Brasília (DF): MS; 2016.

Musheke M, Bond M, Merten S. Individual and contextual factors influencing patient attrition from antiretroviral therapy care in an urban community of Lusaka, Zambia. J Int AIDS Soc 2012; 15:17366.

Myer L, Dunning L, Lesosky M, et al. Frequency of viremic episodes in HIV-infected women initiating antiretroviral therapy in pregnancy: a cohort study. Clin Infect Dis. 2017; 64:422-427.

Gaps, C., Barriers, B., \& Injustices, R. (2018). Miles to go.

Mshana GH, Wamoyi J, Busza J, Zaba B, Changalucha J, Kaluvya S, Urassa M. Barriers to accessing antiretroviral therapy in Kisesa, Tanzania: A qualitative study of early rural referrals to the national program. AIDS Patient Care and STDs. 2006;20(9):649-657. doi: 10.1089/apc.2006.20.649. [PubMed] [CrossRef] [Google Scholar] 
NCASC (2019) National antiretroviral therapy guidelines: National Centre for AIDS \& STD Control. [Internet][cited 2012 March 1]; Available from: http://www.who.int/hiv/pub/guidelines/nepal_art.pdf

Portelli MS, Tenni B, Kounnavong S, Chanthivilay P. Barriers to and facilitators of adherence to antiretroviral therapy among people living with HIV in Lao PDR: a qualitative study. Asia Pacific J Public Heal. 2015;27: NP778NP788

Semvua, S. K., Orrell, C., Mmbaga, B. T., Semvua, H., Bartlett, J. A., \& Boulle, A. A. (2017). Predictors of nonadherence to antiretroviral therapy among HIV infected patients in northern Tanzania. 1-17.

Shrestha R., Copenhaver M., Bazazi A.R., Huedo-Medina T.B., Krishnan A., Altice F.L. A Moderated Mediation Model of HIV-Related Stigma, Depression, and Social Support on Health-Related Quality of Life among Incarcerated Malaysian Men with HIV and Opioid Dependence. AIDS Behav. 2017; 21:1059-1069. doi: 10.1007/s10461-017-1693-x.

Sheet, F., Day, W. A., \& People, V. (2018). 2017 global hiv statistics. 1-6.

Sheet, F., Update, G. A., Hiv, N., \& Hiv, N. (2019). 2018 global hiv statistics. 1-6.

UNAIDS (2018). World AIDS Day Report: Joint United Nations Programme on HIV/AIDS. [Internet][cited 2012 April 12]; Available form: http://www.unaids.org/en/media/unaids

UNAIDS. 90-90-90 An ambitious treatment target to help end the AIDS epidemic.

[Accessed30September,2015];2014 http://www.unaids.org/sites/default/files/media_asset/90-90-90_en_0.pdf.

UNAIDS. Ghana HIV and AIDS Estimates. 2019 [cited 26 Aug 2019]. Available:

https://www.unaids.org/en/regionscountries/countries/ghana

Wang X, Wu Z (2017) Factors associated with adherence to antiretroviral therapy among HIV/AIDS patients in rural China. AIDS patients care and STD. 22,71-80

Wasti SP, Simkhada P, and Van Teijlingen E (2019) Antiretroviral treatment programmes in Nepal. Problems and barriers. Kathmandu University Medical Journal. Vol. 7, No. 3, Issue 27, 306-314.

WHO (2012) Policy collaboration TB/HIV activities: Guidelines for national programmes and other stake holders. World Health Organization. [Internet] [cited 2012 May 16]; Available from: http://whqlibdoc.who.int/publications/2012/9789241503006_eng.pdf

WHO (2013) Adherence to long term therapies - evidence for action. World Health Organization. [Internet] 2003[cited 2012Feb16]; Available from:

http://www.who.int/chp/knowledge/publications/adherence_introduction.pdf

WHO (2015). HIV/AIDS fact sheet: World Health Organization. [Internet] [cited 2012 April 14]; Available from: http://www.who.int/mediacentre

World Health Organization, author. Guideline on when to start antiretroviral therapy and on pre-exposure prophylaxis for HIV. Geneva: World Health Organization; 2015. [Google Scholar]

Setia M. S. (2016). Methodology Series Module 3: Cross-sectional Studies. Indian journal of dermatology, 61(3), 261-264. doi:10.4103/0019-5154.182410

Labhardt ND, Ringera I, Lejone TI, Cheleboi M, Wagner S, Muhairwe J, Klimkait T. When patients fail UNAIDS' last 90 - the 'failure cascade' beyond 90-90-90 in rural Lesotho, Southern Africa: a prospective cohort study. J Int AIDS Soc 2017; 20:21803.

Yehia, B. R., Rebeiro, P., Althoff, K. N., Agwu, A. L., Horberg, M. A., Samji, H., ... Aids, A. (2016). The Impact of Age on Retention in Care and Viral Suppression. 68(4), on HIV stigma, disclosure, and treatment attitudes. 12, 1-12. https:// 413-419. https://doi.org/10.1097/QAI.0000000000000489.The

Zou, J., Yamanaka, Y., John, M., Watt, M., Ostermann, J., \& Thielman, N. (2009). Religion and HIV in Tanzania : influence of religious beliefs doi.org/10.1186/1471-2458-9-75 